
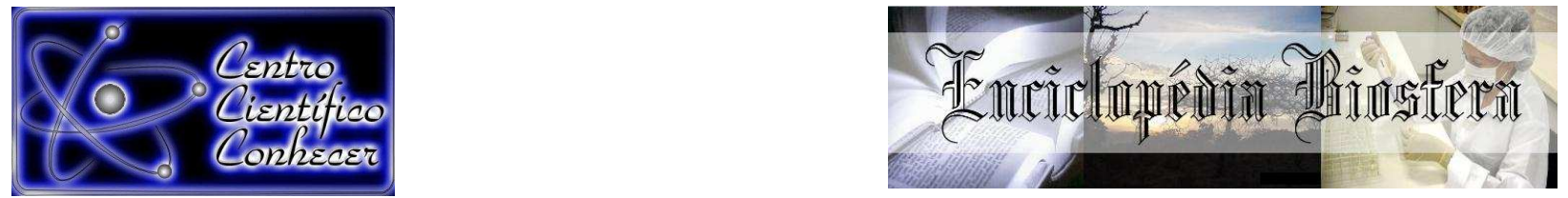

\title{
CARACTERIZAÇÃO MORFOMÉTRICA DA SUB-BACIA HIDROGRÁFICA DO CÓRREGO DA BRISA, ALEGRE, ESPÍRITO SANTO
}

\footnotetext{
Kenia Gomes Tolentino ${ }^{1}$, Amós Mendes da Silva1, Jéferson Luiz Ferrari²

1 Graduando do Curso Superior de Tecnologia em Cafeicultura no Instituto Federal do Espírito Santo - Campus de Alegre, Alegre, ES, Brasil; e-mail: (kesapphire@yahoo.com.br)

2 Professor do Instituto Federal do Espírito Santo - Campus de Alegre, Alegre, ES, Brasil.

Recebido em: 08/09/2015 - Aprovado em: 14/11/2015 - Publicado em: 01/12/2015 DOI: http://dx.doi.org/10.18677/Enciclopedia_Biosfera_2015_111
}

\begin{abstract}
RESUMO
O objetivo deste trabalho foi caracterizar morfométricamente a bacia hidrográfica denominada sub-bacia hidrográfica do córrego da Brisa. O estudo foi realizado em duas etapas: serviço de campo e serviço de escritório. No serviço de campo foram identificadas, georreferenciadas e fotografadas todas as nascentes, as confluências e a foz do córrego da Brisa. No serviço de escritório foi feita a determinação de vários índices morfométricos relacionados à geometria, a topografia e a hidrografia da sub-bacia. Foi realizado também a classificação das nascentes quanto a sua perenidade hídrica e quanto ao seu estado de conservação. O estudo demonstra que a sub-bacia possui área total de $2,89 \mathrm{~km}^{2}$ e perímetro de $7,10 \mathrm{~km}$. A sub-bacia apresenta alta propensão a enchentes, com índice de compacidade no valor de 1,17. A caracterização das nascentes revela um número de 50 nascentes perenes (densidade de nascentes igual a $17,30 \mathrm{~km}^{2}$ ), porém com alto grau de degradação e perturbação ambiental.
\end{abstract}

PALAVRAS-CHAVE: georreferenciamento ,hidrologia, nascentes, morfometria.

\section{CHARACTERIZATION MORPHOMETRIC OF SUB-BASIN CÓRREGO DA BRISA, ALEGRE, ESPÍRITO SANTO}

\begin{abstract}
This study aimed to determine the morphometric characteristics of the watershed Brisa stream, located in Alegre, Espírito Santo, Brazil. The study was conducted in two stages: field service and office service. Field service were identified, georeferenced and photographed all the springs, the confluences and the mouth of the Brisa stream. In office service made the determination of various morphometric indices related to geometry, topography and hydrography of the sub-basin. It was also carried out the classification of springs as their water sustainability and as to their condition. The study shows that the sub-basin has a total area of $2.89 \mathrm{~km} 2$ and a perimeter of $7.10 \mathrm{~km}$. The sub-basin has a high propensity to flooding, with compactness index amounting to 1.17. The characterization of the sources reveals a number of 50 perennial springs (springs density of $17.30 \mathrm{~km}^{2}$ ), but with a high degree of environmental degradation and disturbance.
\end{abstract}

KEYWORDS: hydrology, morphology, georeferencing, springs.

ENCICLOPÉDIA BIOSFERA, Centro Científico Conhecer - Goiânia, v.11 n.22; p. 694 


\section{INTRODUÇÃO}

A crescente demanda por alimentos, desassociada de uma gestão eficiente dos recursos naturais utilizados na produção, tem acarretado a degradação ambiental, notadamente dos recursos hídricos. Os recursos hídricos constituem-se indicadores sensíveis das condições dos ecossistemas, no que se refere aos efeitos do desequilíbrio das interações do solo, água, vegetação e fauna que coexistem, em permanente e dinâmica interação, respondendo às interferências naturais e àquelas de natureza antrópica (SOUZA et al., 2002; SILVA et al., 2012).

Segundo DESTRO (2010), os conflitos resultantes do uso inadequado dos recursos naturais podem ser minimizados quando há o conhecimento das características onde se encontram os recursos naturais, bem como da disponibilidade e capacidade dos recursos, o que está de acordo com os métodos de conservação do solo e da água. Este autor sugere ainda que isso deve ser feito no nível de bacia hidrográfica. Quanto menor o tamanho da bacia hidrográfica maior é o nível de detalhamento das informações.

A bacia hidrográfica é definida como uma localidade da superfície terrestre separada topograficamente entre si, cuja área funciona como um receptor natural das águas da chuva (SOUZA et al., 2010). Todo o volume de água captado não infiltrado é, automaticamente, escoado por meio de uma rede de drenagem das áreas mais altas para as áreas mais baixas, seguindo uma hierarquia fluvial, até concentrarem-se em um único ponto, formando um rio principal. Por este motivo, a bacia hidrográfica é considerada uma unidade de planejamento e gestão ambiental (BERTONI, LOMBARDE NETO, 2008; BERNARDI et al., 2012).

Um dos primeiros e mais comuns procedimentos para o entendimento da dinâmica hidrológica e ambiental no interior de uma bacia hidrográfica é a sua caracterização morfométrica, ou seja, a descrição das medidas fisiográficas da bacia como área, forma, relevo, rede de drenagem, etc (TEODORO et al., 2007; ELESBON et al., 2011, VEIGA et al., 2011). Essas informações físicas da bacia são potencialmente úteis para a elucidação, a compreensão e o planejamento integrado dos recursos naturais, além de ter também aplicação na previsão do grau de vulnerabilidade da bacia a fenômenos como escoamento superficial e inundações, dentre outras finalidades (GEBREHIWOT, et al., 2011; BERTOSSI et al., 2011; FERRARI et al., 2012).

Na sub-bacia hidrográfica do córrego da Brisa, localizada em Alegre, ES, é perceptível sinais de processos erosivos e de uso inadequado dos recursos solo e água. Poucos também são os trabalhos que procuram fazer a caracterização física desta unidade geográfica.

O objetivo deste trabalho foi caracterizar morfométricamente a bacia hidrográfica denominada sub-bacia hidrográfica do córrego da Brisa.

\section{MATERIAL E MÉTODOS}

A sub-bacia hidrográfica do córrego da Brisa fica localizada no município de Alegre, Espírito Santo, Brasil (latitude de 204'30"S e longitude de 4129'46"O). Ressalta-se que o córrego da Brisa é um dos afluentes do rio Itapemirim. 
O clima da região é classificado, segundo a classificação internacional de Köppen, como "Awa", ou seja, tropical quente e úmido, com inverno frio e seco. A temperatura média anual é de $23,1^{\circ} \mathrm{C}$ e precipitação média anual é de $1.341 \mathrm{~mm}$.

A determinação das características morfométricas da sub-bacia hidrográfica do córrego da Brisa foi realizada no período de julho a setembro de 2014, divida em duas etapas: serviço de campo e serviço de escritório desenvolvido no Laboratório de Geoprocessamento do Instituto Federal do Espírito Santo - Campus de Alegre. No serviço de campo foram identificadas, georreferenciadas e fotografadas todas as nascentes, as confluências e a foz do córrego da Brisa. O georreferenciamento foi feito por meio do uso de receptor Global Positionig System (GPS), marca Garmim®, e pré-configurado para o Datum Word Geodetic System 84 (WGS 84) e formato de posição Universal Transversa de Mercator (UTM). O registro fotográfico foi realizado por uma máquina fotográfica Samsung, modelo WB 150.

As nascentes foram classificadas quanto a sua perenidade hídrica em perenes, interminentes e temporárias, conforme VALENTE \& GOMES (2005); e quanto ao seu estado de conservação em conservadas, pertubadas e degradadas, conforme PINTO et al. (2004).

Segundo VALENTE \& GOMES (2005), as nascentes perenes se manifestam durante o ano todo com variações de vazão ao longo do mesmo; as nascentes intermitentes fluem durante a estação chuvosa, mas secam durante a estação seca; e as nascentes temporárias ou efêmeras ocorrem somente após à precipitação.

De acordo com PINTO et al. (2004) as nascentes conservadas são aquelas que apresentam, pelo menos, $50 \mathrm{~m}$ de vegetação natural em seu entorno, a partir do olho d'água. As nascentes perturbadas, diferentemente, são aquelas que não apresentam $50 \mathrm{~m}$ de vegetação natural em seu entorno, mas exibem bom estado de conservação; e as nascentes degradadas já são aquelas que tem alto grau de perturbação, muito pouca vegetada, solo compactado, presença de gado, sinais de erosões e até voçorocas.

O serviço de laboratório foi realizado o descarregamento dos dados de GPS obtidos a campo, a integração de dados geoespaciais e a determinação dos índices morfométricos relacionados à geometria, a topografia e a hidrografia da sub-bacia.

O descarregamento dos dados foi feito por meio do uso do programa

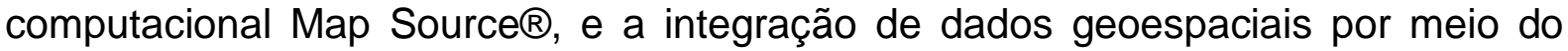
programa Google Earth Pro®. Foi utilizado o modelo digital de elevação da missão Shuttle Radar Topographic Mission 3 (SRTM 3), de 90 m de resolução espacial, e uma imagem orbital do sensor Pleiades, de outubro de 2014, de $50 \mathrm{~cm}$ de resolução espacial.

Com a integração dos dados geoespaciais foi possível, por meio das funcionalidades do programa Google Earth Pro®, delimitar a sub-bacia hidrográfica, mapear a hierarquia fluvial e extrair os dados necessários para a determinação dos índices morfométricos. Nas Tabelas 1, 2 e 3 são apresentadas, respectivamente os índices morfométricos organizados quanto as características geométricas, de relevo e da rede de drenagem da sub-bacia do córrego da Brisa. 
TABELA 1 - Índices e metodologias usadas para o estudo morfométrico da subbacia hidrográfica do córrego da Brisa, quanto às características geométricas

\begin{tabular}{|c|c|c|}
\hline \multicolumn{3}{|c|}{ Características geométricas } \\
\hline Índices & Notações & Metodologias \\
\hline Área total & $A$ & \\
\hline Coeficiente de compacidade & $K c=0,28 * \frac{P}{\sqrt{A}}$ & $\begin{array}{l}\text { Cardoso et al. } \\
\qquad(2006)\end{array}$ \\
\hline Comprimento axial & $L_{\text {axial }}$ & \\
\hline Fator de forma & $K f=\frac{A}{L_{\text {axial }}^{2}}$ & $\begin{array}{l}\text { Mosca } \\
(2003)\end{array}$ \\
\hline Índice de circularidade & $I c=\frac{12,57^{*} A}{P^{2}}$ & $\begin{array}{l}\text { Borsato e Martoni } \\
\qquad(2004)\end{array}$ \\
\hline Perímetro total & $P$ & \\
\hline Razão de elongação & $\operatorname{Re}=1,128 *\left(\frac{A^{0,5}}{L_{\text {axial }}}\right.$ & $\begin{array}{l}\text { Mosca } \\
(2003)\end{array}$ \\
\hline
\end{tabular}

$\mathrm{A}=$ Área total; $\mathrm{Kc}=$ Coeficiente de compacidade; $\mathrm{P}=$ Perímetro total; $\mathrm{L}_{\text {axial; }} \mathrm{Kf}=\mathrm{Fator}$ de forma; $\mathrm{IC}=$ Índice de circularidade; Re Razão de elongação

TABELA 2 - Índices e metodologias usadas para o estudo morfométrico da subbacia hidrográfica do córrego da Brisa, quanto às características do relevo

\begin{tabular}{llc}
\hline \multicolumn{3}{c}{ Características do relevo } \\
\hline İndices & Notações & Metodologias \\
\hline Razão do relevo & $R r=\frac{\Delta_{\text {altimérica }}}{L_{\text {axial }}}$ & Rossi e Pfeifer (1999) \\
\hline Rr= Razão do relevo; $\Delta_{\text {and }}$ &
\end{tabular}

TABELA 3 - Índices e metodologias usadas para o estudo morfométrico da subbacia hidrográfica do córrego da Brisa, quanto às características da rede de drenagem

\section{Características da rede de drenagem}

\begin{tabular}{|c|c|c|}
\hline İndices & Notações & Metodologias \\
\hline $\begin{array}{l}\text { Comprimento do curso } \\
\text { d'água principal }\end{array}$ & $L p$ & \\
\hline $\begin{array}{l}\text { Comprimento total dos } \\
\text { cursos d'água }\end{array}$ & $L t$ & \\
\hline $\begin{array}{l}\text { Declividade do curso } \\
\text { d'água principal entre a } \\
\text { foz e a nascente }\end{array}$ & $S 1=\frac{\left(\operatorname{Cota}_{\max x}-\operatorname{Cota}_{\min .}\right)}{L p}$ & $\begin{array}{c}\text { Cecílio e Reis } \\
\text { (2006) }\end{array}$ \\
\hline
\end{tabular}




\begin{tabular}{|c|c|c|}
\hline Densidade de confluência & $D c=\frac{N_{\text {confluências }}}{A}$ & $\begin{array}{l}\text { Cecílio e Reis } \\
\quad(2006)\end{array}$ \\
\hline Densidade de drenagem & $D d=\frac{L t}{A}$ & $\begin{array}{l}\text { Cardoso et al. } \\
(2006)\end{array}$ \\
\hline Densidade hidrográfica & $D h=\frac{N_{\text {cursos }}}{A}$ & $\begin{array}{l}\text { Borsato e Martoni } \\
\qquad(2004)\end{array}$ \\
\hline Densidade de nascentes & $D n=\frac{N_{\text {nascentes }}}{A}$ & $\begin{array}{c}\text { Cecílio e Reis } \\
(2006)\end{array}$ \\
\hline $\begin{array}{l}\text { Extensão média do } \\
\text { escoamento superficial }\end{array}$ & $I=\frac{A}{4 L t}$ & $\begin{array}{l}\text { Cecícilo e Reis } \\
(2006)\end{array}$ \\
\hline Índice de rugosidade & $H d=\Delta_{\text {altimétria }} * D d$ & $\begin{array}{l}\text { Bertoni et al. } \\
\quad(2007)\end{array}$ \\
\hline Ordem dos cursos d'água & Ord & $\begin{array}{c}\text { Strahler } \\
\text { (1988) }\end{array}$ \\
\hline
\end{tabular}

$\mathrm{Cr}=$ Coeficiente de rugosidade; $\mathrm{Dd}=$ Densidade de drenagem; $\mathrm{Lp}=$ Comprimento do curso d'água principal; $\mathrm{Lt}=$ Comprimento total dos cursos d'água; $\mathrm{S} 1=$ Declividade do curso d'água principal entre a foz e a nascente; Cota $_{\text {máx. }}=$ Altitude máxima; Cota $_{\min }=$ Altitude mínima; $D c=$ Densidade de confluência; $N_{\text {confluências }}=$ Número de confluências; $A=$ Área da bacia; $D n=$ Densidade hidrográfica; $\mathrm{N}_{\text {cursos }}=$ Números de cursos d'água; $\mathrm{Dn}=$ Densidade de nascentes; $\mathrm{N}_{\text {nascentes }}=$ Número de nascentes; $\mathrm{I}=$ Extensão média do escoamento superficial; $\mathrm{Hd}=$ Índice de rugosidade; $\Delta_{\text {altimétrica }}=$ Amplitude altimétrica; Ord= Ordem dos cursos d'água.

A hierarquização fluvial do córrego da Brisa foi feita segundo o critério proposto por Horton e modificado por Strahler (STRAHLER, 1988), na qual os pequenos cursos d'água que não têm tributários, são de ordem 1; quando dois cursos d'água de mesma ordem se encontram, o canal formado é de ordem imediatamente superior; da junção de dois canais de ordens diferentes resulta um outro cuja ordem será igual a maior dentre os formadores.

\section{RESULTADOS E DISCUSSÃO}

Os resultados da análise morfométrica da sub-bacia hidrográfica do córrego da Brisa está apresentado na Tabela 4.

A sub-bacia do córrego da Brisa pode ser classificada como uma unidade espacial pequena, considerando que sua área total de drenagem foi de $2,89 \mathrm{~km}^{2} \mathrm{e} o$ perímetro de $7,10 \mathrm{~km}$ (Tabela 4). Este resultado configura a sub-bacia hidrográfica do córrego da Brisa como uma unidade espacial ideal para a elaboração e condução de projetos conservacionistas de solo e da água, sob a ótica de microbacias hidrográficas (BERTONI \& LOMBARDI NETO, 2008). Estes autores consideram que bacias hidrográficas de 1.000 a 5.000 ha possibilitam um planejamento global dos problemas do meio ambiente, atingindo as esferas social, política, econômica e educacional. 
TABELA 4 - Resultados da análise morfométrica da sub-bacia hidrográfica do córrego da Brisa

\begin{tabular}{|c|c|}
\hline \multicolumn{2}{|c|}{ Características Geométricas } \\
\hline Área total $(\mathrm{A})$ & $2,89 \mathrm{~km}^{2}$ \\
\hline Coeficiente de compacidade (Kc) & 1,17 \\
\hline Comprimento axial ( $\left.\mathrm{L}_{\text {axial }}\right)$ & $2,55 \mathrm{~km}$ \\
\hline Fator de forma (Kf) & 0,44 \\
\hline Índice de circularidade (Ic) & 0,72 \\
\hline Perímetro total $(\mathrm{P})$ & $7,10 \mathrm{~km}$ \\
\hline Razão de elongação $(R e)$ & 0,75 \\
\hline \multicolumn{2}{|c|}{ Características do relevo } \\
\hline Razão do relevo (Rr) & $0,09 \mathrm{~km}$ \\
\hline Altitude menor & $117 \mathrm{~m}$ \\
\hline Altitude maior & $440 \mathrm{~m}$ \\
\hline Comprimento do curso d'água principal (Lp) & $2,55 \mathrm{~km}$ \\
\hline Comprimento total dos cursos d'água (Lt) & $8,30 \mathrm{~km}$ \\
\hline \multicolumn{2}{|c|}{ Características da rede de drenagem } \\
\hline $\begin{array}{l}\text { Declividade do curso d'água principal entre a foz e } \\
\text { a nascente (S1) }\end{array}$ & $0,09 \mathrm{~m}$ \\
\hline Densidade de confluência (Dc) & 16,61 conf, $\mathrm{km}^{-2}$ \\
\hline Densidade de drenagem (Dd) & $2,87 \mathrm{~km} \mathrm{~km}^{-2}$ \\
\hline Densidade hidrográfica (Dh) & 19,72 cursos $\mathrm{km}^{-2}$ \\
\hline Densidade de nascentes (Dn) & $17,30 \mathrm{~km}^{-2}$ \\
\hline Extensão média do escoamento superficial (I) & 0,09 km \\
\hline Índice de rugosidade $(\mathrm{Hd})$ & $0,67 \mathrm{~km}$ \\
\hline Ordem dos cursos d'água (Ord) & 4 \\
\hline
\end{tabular}

Fonte: Elaborado pelos autores

Considerando-se que caracterização física de uma bacia hidrográfica possibilita o estabelecimento de relações e comparações entre as características físicas e os dados hidrológicos, pode-se dizer com base no valor do coeficiente de compacidade $(\mathrm{Kc})$, que apresentou valor de 1,17 , que a sub-bacia hidrográfica do córrego da Brisa tem alta propensão a ocorrência de enchentes. De acordo com VILELLA \& MATTOS (1975), este índice relaciona a forma da bacia como um círculo. Quando o valor deste índice é igual a um (1), significa que a bacia se assemelha a forma de um círculo, sendo, portanto, mais susceptível a enchentes, pois sua equação constitui em uma relação entre o perímetro da bacia e a circunferência de um círculo de área igual à da bacia. O Índice de circularidade (Ic) da sub-bacia hidrográfica do córrego da brisa apresentou valor de 0,72 , ou seja, valor próximo de 1 , ratificando a propensão da sub-bacia à enchentes pois a concentração de água no tributário principal será maior (DÉSTRO et al., 2010).

Somente o fator de forma (Kf), com índice de 0,44, que está abaixo de 0,50 significando não estar sujeita a enchentes, pois uma bacia com fator de forma baixo terá maiores chances de apresentar um formato mais retangular, ou seja, mais estreita e longa, portanto, menos sujeita a enchentes do que outra de mesmo tamanho, mas com fator de forma maior. Há menos possibilidade de ocorrência de chuvas intensas cobrindo simultaneamente toda a extensão da bacia e também, a contribuição dos tributários atinge o curso d'água principal em vários pontos ao 
longo do mesmo, afastando-se, portanto da condição ideal da bacia circular (FERREIRA et al., 2010).

A densidade de drenagem da sub-bacia hidrográfica do córrego da Brisa foi de $2,87 \mathrm{~km} \mathrm{~km}^{-2}$, podendo ser caracterizada como uma sub-bacia de capacidade de drenagem regular. De acordo com VILLELA \& MATTOS (1975) este índice pode variar de $0,5 \mathrm{~km} / \mathrm{km}^{-2}$, em bacias com drenagem pobre, a $3,5 \mathrm{~km} / \mathrm{km}^{-2}$ ou mais, nas bacias excepcionalmente bem drenadas.

Por se tratar de uma forma mais simples de se representar a densidade de drenagem de uma bacia, o índice densidade de confluência (Dc) não apresenta a mesma precisão, mas serve para se avaliar a drenagem da bacia (CECÍLIO \& REIS, 2006). Verifica-se que a sub-bacia do córrego da Brisa apresenta o índice de uma confluência para cada $16,61 \mathrm{~km}^{2}$ de área de bacia, portanto, bem drenada, o que é confirmado pela densidade de drenagem (Dd).

A densidade hidrográfica (Dh) é um índice importante, pois analisa a capacidade de determinada área de gerar novos cursos d'água e tende a variar de maneira constante com a densidade de drenagem (Dd) (BORSATO \& MARTONI ,2004). Portanto, baseado nos valores do primeiro índice $\left(19,72\right.$ cursos $\left.\mathrm{km}^{-2}\right)$ é possível estimar a densidade de drenagem através de uma relação empírica, resultando a Dd em $2,87 \mathrm{~km} \mathrm{~km}^{-2}$.

A hierarquização do sistema de drenagem da sub-bacia hidrográfica do córrego da Brisa está apresentada na Figura 1. Nota-se que o córrego da Brisa é constituído pelo curso d'água principal mais os seus tributários.

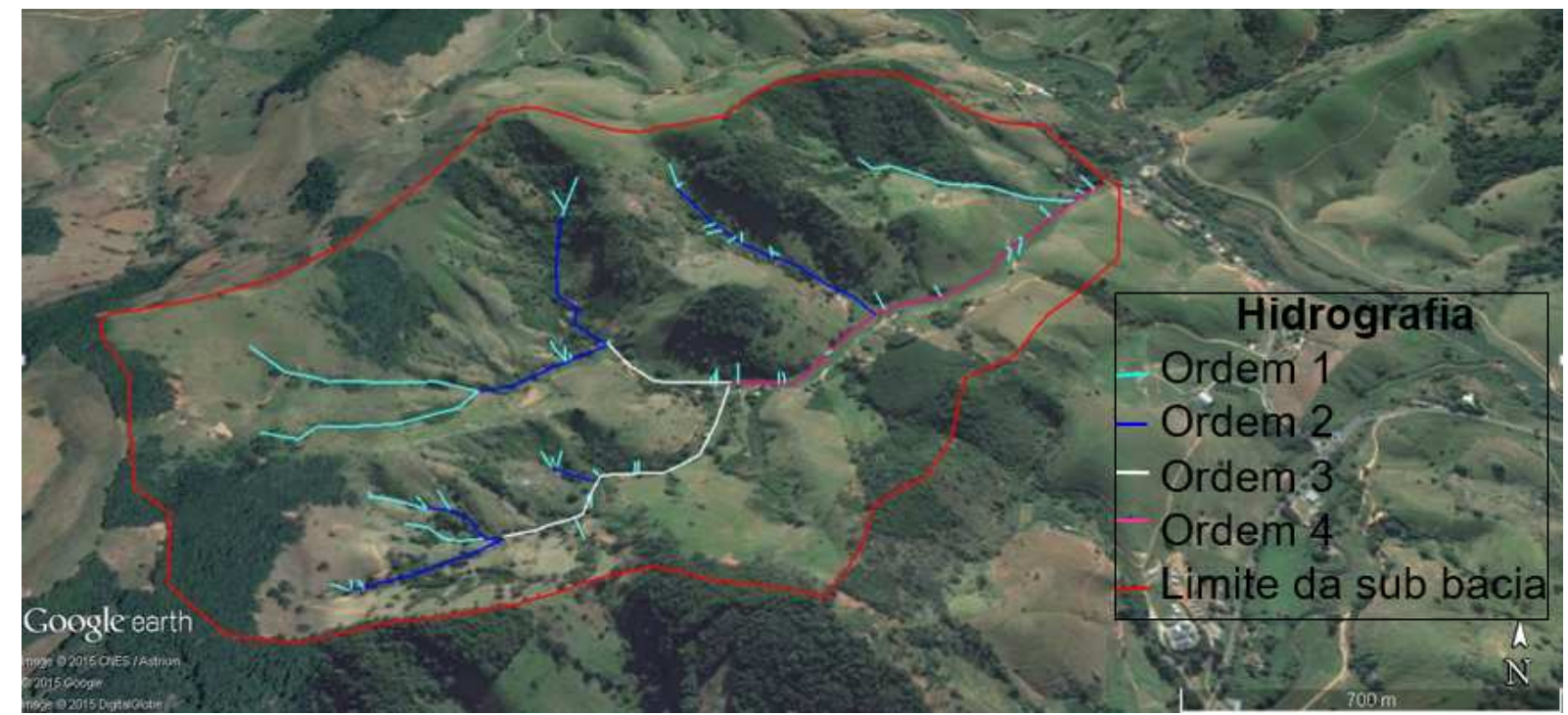

FIGURA 1 - Hierarquização do sistema de drenagem da sub-bacia hidrográfica do córrego da Brisa.

Fonte: Elaborado pelos autores

Segundo o critério proposto por Horton e modificado por Strahler (STRAHLER, 1988), a ramificação do sistema de drenagem exibe um padrão tipo dentrítico com grau 4 de ordenamento do curso d'água. Este valor é considerado alto haja vista o pequeno tamanho da bacia. Segundo BERTONI \& LOMBARDI NETO, (2008), quanto mais ramificada for a rede mais eficiente será o sistema de drenagem. A classificação possibilita o entendimento da dinâmica global do sistema hidrográfico e a identificação das unidades que o compõem. 
Na Tabela 5 são mostrados os resultados da classificação das nascentes da sub-bacia hidrográfica do córrego da Brisa quanto a sua perenidade e ao seu estado de conservação. Nota-se que, de um total de 50 nascentes analisadas, $78 \%$ das nascentes são perenes e $88 \%$ das nascentes apresentam sinais de degradação.

TABELA 5 - Resultados da classificação das nascentes da sub-bacia hidrográfica do córrego da Brisa em relação a perenidade hídrica e ao estado de conservação

\begin{tabular}{lcc}
\hline \multicolumn{2}{c}{ Classificação em relação a perenidade hídrica das nascentes } \\
\hline \multicolumn{2}{c}{ Classes } & Número (\%) \\
\hline Perenes & $78 \%$ \\
Interminentes & $22 \%$ \\
Temporárias & $0 \%$ \\
\hline \multicolumn{2}{c}{ Classificação quanto ao estado de conservação das nascentes } \\
\hline \multicolumn{2}{c}{ Classes } & Número (\%) \\
\hline Perturbadas & $12 \%$ \\
Degradadas & $88 \%$ \\
Conservadas & $0 \%$ \\
\hline
\end{tabular}

Fonte: Elaborado pelos autores

O número de nascentes consideradas degradadas é representativo. Ao realizar a etapa de campo deste trabalho foi possível constatar que a atividade de pecuária extensiva, muito utilizada nesta área, contribui para estes números. O gado pasteja até bem próximo das nascentes, sem qualquer impedimento físico para evitar o pisoteio sobre olho d'água. Os $12 \%$ de nascentes perturbadas, são utilizadas para o consumo humano. Elas foram protegidas apenas com manilhas ou caixas de concreto e tampadas. Não há nenhuma nascente conservada com presença de pelo menos $50 \mathrm{~m}$ de vegetação natural em seu entorno, a partir do olho d'água.

De acordo com a perenidade hídrica das nascentes, observa-se que a maioria das nascentes (78\%) são classificadas como perenes (Tabela 5), ou seja, perduram por todo o ano com água corrente. As nascentes classificadas como intermitentes representam $22 \%$ e, as temporárias, $0 \%$.

\section{CONCLUSÕES}

A sub-bacia hidrográfica do córrego da Brisa possui área total de $2,89 \mathrm{~km}^{2} \mathrm{e}$ perímetro de $7,10 \mathrm{~km}$. A sub-bacia apresenta alta propensão a enchentes, com índice de compacidade no valor de 1,17 . A caracterização das nascentes revela um número de 50 nascentes perenes (densidade de nascentes igual a $17,30 \mathrm{~km}^{-2}$ ), porém com alto grau de degradação e perturbação. Espera-se que estas informações podem subsidiar e estimular o planejamento conservacionista dos recursos naturais da referida sub-bacia.

\section{REFERÊNCIAS}

BERNARDI, E. C. S.; PANZIERA, A. G.; BURIOL, G. A.; SWAROWSKY, A.Bacia hidrográfica como unidade de gestão ambiental. Disciplinarum Scientia. Série: Ciências Naturais e Tecnológicas, Santa Maria, v. 13, n. 2, p. 159-168, 2012. 
BERTONI, J.; LOMBARDE NETO, F. Conservação do Solo. São Paulo: Ícone, 2008. 355p.

BERTOSSI A. P. A.; KLIPPEL H. V.; PELUZIO O. M. T.; MENEZES C. P. J.; CECÍlIO A. R. Análise Morfométrica Da Sub-Bacia Do Córrego Horizonte, AlegreEs, Utilizando O Sistema De Informação Geográfica (SIG). Núcleus, v. 8, n. 2, p 209-218, 2011.

BORSATO, F. H.; MARTONI, A. M. Estudo da fisiografia das bacias hidrográficas urbanas no município de Maringá, estado do Paraná. Acta Scientiarum. Human and Social Sciences, v.26, n.2, p.273-285, 2004.

CECÍLIO, R. A.; REIS, E. F. dos. Apostila didática: Manejo de bacias hidrográficas. Alegre: Universidade Federal do Espírito Santo - UFES/CCA-UFES, 2006. 10p. <http:// blog.fimes.edu.br/gildomar/files/2010/04/18028090manejo-debacias-hidrograficas1.pdf>. 05 Out. 2012.

DÉSTRO, G. F. G. Diagnóstico físico-conservacionista no estudo dos conflitos de uso da terra em microbacias hidrográficas. Revista Brasileira de Ciências Agrárias, v.5, n.4, p.525-534, 2010.

ELESBON, A. A. A.; GUEDES, H. A. S.; SILVA, D. D. da; OLIVEIRA, .I de C. Uso de dados SRTM e plataforma SIG na caracterização morfométrica da bacia hidrográfica do Braço Norte do Rio São Mateus - Brasil. Rem: Revista Escola de Minas v.64, n.3, p.281-288, 2011

FERRARI, L. J.; SILVA, F. S.; SANTOS, R. A.; GARCIA, F. R. Análise morfométrica da sub-bacia hidrográfica do córrego Horizonte, Alegre, ES. Agrária. 2013.

FERREIRA, T. S. W. C.; LIMA, S. C. de.; CAVALCANTI S. C. L. de.; SANTOS O. H. A. de. Caracterização morfométrica da bacia hidrográfica do açude cachoeira II, no município de serra talhada - PE, Brasil. VI Seminário Latino Americano de Geografia Física II, Seminário Ibero Americano de Geografia Física Universidade de Coimbra. 2010. < http://www.uc.pt/fluc/cegot/VISLAGF/actas/tema2/clarisse>. 04 Set. 2015.

GEBREHIWOT, S. G.; IISTEDT, U.; GÄRDENAS, A.I ., BISHOP, K. Hidrological characterization of watersheds in the Blue Nile Basin, Ethiopia. Hydrology and Earth System Sciences. v.15, p. 11-20, 2011.

GOOGLE EARTH PRO ®. Programa computacional, versão Google Eath Pro® 2014.

HORTON R. E. Erosional development of streams and their drainage basins; hydrophysical approach to quantitative morphology, in Chow, Ven Te; Maidment, D. 1945.

MAP SOURCE®. Programa computacional, versão Map Source® 2010. 
MOSCA, A. A. O. Caracterização hidrológica de duas microbacias visando a identificação de indicadores hidrológicos para o monitoramento ambiental do manejo de florestas plantadas. Piracicaba-SP: Universidade de São Paulo/Escola Superior de Agricultura "Luiz de Queiroz", 2003. 88p. Dissertação Mestrado.

PINTO, L. V. A.; BOTELHO, S. A.; DAVIDE, A. C.; FERREIRA, E. Estudos das nascentes da bacia hidrográfica do Ribeirão Santa Cruz, Lavras, MG. Scientia Forestalis, Piracicaba, n. 65, p. 197-206, 2004.

ROSSI, M.; PFEIFER, R. M. Remoção de material erodido dos solos de pequenas bacias hidrográficas no Parque Estadual da Serra do Mar em Cubatão (SP). Bragantia, v.58, n.1, p.141-156, 1999.

SILVA, I. S. da. CRISPIM, Q. J. de. Aplicação De Técnicas De Recuperação E Proteção De Nascentes E Sua Importância Para A Comunidade Local: O Caso Da Bacia Hidrográfica Do Rio Vale Da Paz No Município De Campo Mourão - PR. Anais... VII Encontro de Produção Científica e Tecnológica. 2012.

SOUZA, F. F. de. Bacias hidrográficas. UFSCAR. 2010. Disponível em < http://www.ufscar.br/aprender/aprender/2010/06/bacias-hidrograficas/>. Acesso: 04 Set. 2015

SOUZA. C. G. Caracterização e manejo integrado de bacias hidrográficas. Belo Horizonte: EMATER, 2002. 124p.

STRAHLER A. N. Quantitative geomorphology of drainage basins and channel networks, section 4 - II, in Chow, Ven Te; Maidment, D. R; Mays, L. W. (1988). Applied Hydrology, McGraw-Hill, New York.

TEODORO, V. L. I.; TEXEIRA, D.; COSTA, D. J. L.; FULLER, B. B. O conceito de bacia hidrográfica e a importância da caracterização morfométrica para 0 entendimento da dinâmica ambiental local. Revista Uniara, n.20, p. 137-156, 2007.

VALENTE, O. F.; GOMES, M. A. Conservação de Nascentes: Hidrologia e Manejo de Bacias Hidrográficas de Cabeceiras. EditoraViçosa - MG, 2005.

VEIGA, A. M.; CARDOSO, M. R.; LINO, N. C. Caracterização Hidromorfológica da Bacia do Rio Meia Ponte. In Anais XIX Simpósio Brasileiro de Recursos HídricosABRH. Maceió-AL. Novembro.2011.

VILLELA, S. M.; MATTOS, A. Hidrologia aplicada. São Paulo: McGraw-Hill do Brasil, 1975. 245 p. 